\title{
Process audit on quality of out-patient records using WHO chart audit as a tool for training interns and improving quality of service delivery in an urban health training centre
}

\author{
Prabha Thangaraj ${ }^{1}$, Thomas V. Chacko ${ }^{2, *}$ \\ ${ }^{1}$ Assistant Professor, Dept. of Community Medicine, Chennai Medical College Hospital and Research Centre, Trichy, Tamil \\ Nadu, ${ }^{2}$ Dean \& Professor, Dept. of community Medicine \& Medical Education, Believers Church Medical College, Thiruvalla, \\ Kerala, India
}

*Corresponding Author:

Email: drthomasvchacko@gmail.com

\begin{abstract}
Patient care documentation is an important component of health care service delivery and continuity of care within the health system. Case documentation audit is a good tool to improve the quality of service and to help train budding doctors about the expected standard of care. This study was done as part of a Competent Interns training program for primary care as well as a quality improvement program to improve patient care documentation in an Urban health training center. The specific objectives were to identify the gaps in practice and serve as the baseline quality of Out-patient case records and using the gaps in practice to conduct an educational intervention among Interns. The effectiveness of this intervention was then measured by noting the changes seen upon re-audit.

Materials and Methods:

1. Study design: Intervention study (Educational) following a process audit

2. Study sample: All new Out-patient case records from November 2014 to January 2015 for baseline study and new Outpatient case records from April to June 2015 for re-audit after setting targets

3. Setting: Primary health care training center catering to an urban area.

4. Analysis: Results are expressed in percentage of records with adequate documentation for each items in the checklist. Overall mean score \pm standard deviation for records were calculated (pre and post audit separately) and $t$ test was done to detect for statistically significance ( $1 \%$ level of significance) following the educational intervention.

Results: Baseline audit ( $\mathrm{n}=110)$ showed 100\%, $97 \%$ and $95 \%$ records had documented patients details, patient complaints and physical examination on case sheets respectively. There was poor documentation of drug allergies (1\%), review date $(36 \%)$ and name of the examining doctor or intern (3\%).Following the educational intervention during the re-audit $(n=75)$ there was overall improvement in case sheet recording practice $(\mathrm{t}=15.34 ; \mathrm{p}<0.001)$ among the health care staff.

Conclusions: Identification of gaps in documentation practice using a validated standard of care audit tool helps. Training Interns got to learn this useful managerial skill so that they are trained for quality improvement at Primary Care level.
\end{abstract}

Keywords: Case sheets audit, Competent Interns, Gap identification.

\section{Introduction}

Medical record is a systematic documentation of a patient's personal, social and medical history, clinical findings, investigation, diagnosis, treatment, follow up and final outcome. ${ }^{1}$ Documentation of all relevant patient details in the case sheet is not only necessary in tertiary care setting but also in primary health care which mainly caters to out-patient services. Accurate recording of information can help to plan and evaluate patient's response to treatment and its effectiveness. It also ensures continuity of care among multiple providers like the medical officers and interns undergoing training on a short term basis in a health training centre. In such settings where many components of the primary care service is delegated to and delivered through a team of paramedical professionals, the quality of care a patient receives depends directly on the accuracy and legibility of patient information recorded. Hence physicians and others who the enter information into patient records must know the importance of filling records and the medical implication of failing to do so. By encouraging health providers to document record properly, it is expected that it will improve their quality of practice along with patient care. It has been documented that regular auditing of patient case record is essential for better patient care. ${ }^{2}$ Moreover, details provided in the case sheet can serve many other purposes like research, administration, follow up and handling medical negligence suits. ${ }^{3,4}$ Periodic monitoring of case-sheets can indirectly assess the quality of care given, and by doing so, it can be improved.

The Urban Health Training Centre (UHTC) under the Community Medicine department of PSG Institute of Medical College (PSG IMSR), Coimbatore provides primary health care to 40,000 population in an urban area. It is a peripheral health care unit with the health team comprising of Medical officers, Interns (Training doctors), Staff nurse, Nursing assistants and Medical social worker under the supportive supervision of a faculty member. Interns are posted for a period of one month at the UHTC and another month in Rural Health 
Training Center during their 12 month period of compulsory rotatory internship programme in order to ensure a Graduate becomes familiar and competent to work in primary care setting as an Indian Medical Graduate. During their posting, they are expected to undergo training to provide basic medical care, provide preventive services and health education under the guidance of the medical officers. Interns are also expected to know the importance of documenting patient details in the case sheets. This becomes essential for the Center for ensuring continuity of care since the Interns keep changing every month. Previous history, clinical finding, investigations done, diagnosis and treatment given can be known correctly only if it was document properly. Proper record keeping is still in its early stage in Indian scenario, ${ }^{4}$ therefore emphasis of proper documentation of patient details needs to be made early in their medical career to develop the habit of maintaining proper patient case sheet.

This study was done as part of a "Competent Interns Training Program" for primary care as well as a quality improvement initiative to improve patient care documentation in an Urban health training center. The specific objectives were 1) to identify the baseline quality of Out-patient case records using WHO Standard of care in OP documentation, 2) identify the common gaps in practice in their OP documentation, and 3) to conduct an educational intervention among Interns and then measure its effectiveness by noting the changes in practice through a post intervention audit.

\section{Methodology}

The current educational interventional study was conducted at the Urban Health Care Training Centre (UHTC) of a medical college that provides Primary Care and acts as a training center for Indian medical Graduates (M.B.B.S) as well as Nursing, Pharmacy and Physiotherapy professional course students. Extensive search of literature was done to identify a validated case sheet audit tool for out-patient (OP) case sheet applicable to a primary care setting. Outpatients are those attending and receiving health care services from health providers without being admitted. ${ }^{5}$ Modification of the World Health Organization (WHO) Standard Chart Audit Tool ${ }^{6}$ for primary health centre was done to suite our Indian setting. Content validation was done by experts in the department of community medicine, PSG Institute of Medical College (IMSR). Ethical approval was obtained before conducting the study from Institutional Human Ethics Committee, PSG Institute of Medical Science and Research, Coimbatore.

The Audit tool: A total of 14 items from the WHO Standard Chart Audit Tool were included in the audit tool used in the present study namely: patient details (name, age and sex), occupation, history of drug allergy, medical history, family \& social history, eligibility of writing, examining doctor/CRRI's name, patient complaints, physical examination, final diagnosis, medication dose, duration of medication, review date and counter sign by medical officer. A score of 1 was given for each item that was documented in the case sheet and 0 if it was not. The maximum score of each case sheet was 14. Legibility of handwriting was assessed by two members other than the principle investigator. If two of the three members in audit team could read the writing it was considered legible. Counter sign by the medical officer was considered essential in those case sheet seen by the CRRIs since they are authorized to prescribe drugs only under the supervision of a registered medical practitioners.

The Study sample: All new OP case records from $1^{\text {st }}$ November 2014 to $15^{\text {th }}$ January 2015 were included for the baseline study. Revisit or follow-up case sheets were excluded. For re-audit, after training the interns about standard of care for OP chart documentation, new OP case records from $21^{\text {st }}$ April to $25^{\text {th }}$ June 2015 were taken up for re-audit. A total of 110 OP case sheets were audited for baseline and 75 OP case sheets were taken up for re-audit to capture the change/ improvement in performance as an indicator of effectiveness of the educational intervention.

The Educational Intervention: Following the baseline audit results, a training session was conducted at the centre among all the health care providers with special focus on Interns. The audit tool as representing the Standard of Care stated by WHO for Primary Care settings and its purpose was explained without disclosing the results of baseline audit but setting a targeted improvement in compliance to the standard of care expected. An interactive session for 30 minutes was conducted with the aid of power point presentation. A print out of the audit check list was displayed on the intern's desk. Interns were asked to communicate the same to their fellow batch mates in the next rotation to ensure self-sustainability of the intervention. Medical officers were also asked to ensure that the case sheets are maintained according to the set guidelines and to supervise the interns.

\section{Statistical analysis}

For all analysis SPSS version 19 was used. The proportion of case sheet documenting each item on the audit list was expressed in percentage. Average score for case sheet was expressed in mean with standard deviation. Unpaired $\mathrm{t}$-test was done between the baseline and re-audit score to assess the effectiveness of educational intervention given to the medical staffs. 
Flow Chart 1: Flow diagram showing the steps of methodology

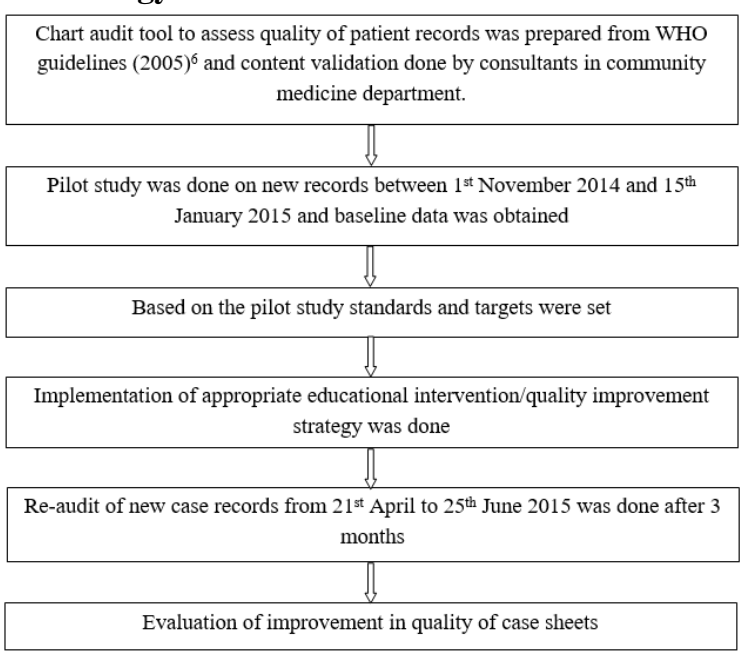

\section{Results}

At the Baseline Audit, the mean score of case sheets was $8.6 \pm 1.70$ out of 14 (Table 1). All records had documented patient's details (name, age and sex).
Documentation of patient symptoms, physical examination and legibility of writing was seen in more than $95 \%$ of case sheet. We identified poor recording of drug allergy $(1.8 \%)$ and name of the examining doctor $(2.7 \%)$. None of the record had documented all the 14 criteria. Only $9 \%$ had a score of 10 and more.

Post-audit score showed a mean of $12.4 \pm 1.22$ out of 14 , which was found to be statistically significant from the baseline score $(\mathrm{t}=15.34, \mathrm{p}<0.001)$ (Table 1). We found a drastic improvement from the baseline upon Post-audit in the areas of documentation of the doctor's name (94.6\%) and drug allergy history $(25.3 \%)$. Even the recording of review date and counter sign of the medical officer increased from $36.3 \%$ to $94.6 \%$ and $10.9 \%$ to $77.3 \%$ respectively. In spite of improvement in the recording of case, the set target in standard of care was not achieved for the following areas- drug allergies, medical history, legibility of writing and medication. Of these, only illegibility of writing decreased from $98.1 \%$ in baseline audit to $80 \%$ during the post intervention audit.

Table 1: Educational Effectiveness: Descriptive data of OP case sheet for baseline and post intervention chart audit

\begin{tabular}{|l|l|l|l|l|l|l|l|}
\hline & $\begin{array}{l}\text { Case sheet } \\
\text { reviewed } \\
\text { (N) }\end{array}$ & $\begin{array}{l}\text { Minimum } \\
\text { score out } \\
\text { of } \mathbf{1 4} \\
\text { items }\end{array}$ & $\begin{array}{l}\text { Maximum } \\
\text { score out } \\
\text { of } \\
\text { items }\end{array}$ & $\begin{array}{l}\text { Mean } \\
\text { Score } \\
\text { of 14 } \\
\text { items }\end{array}$ & $\begin{array}{l}\text { Standard } \\
\text { Deviation }\end{array}$ & t-value & p-value \\
\cline { 1 - 6 } Baseline & 110 & 4 & 12 & 8.6 & \pm 1.70 & 15.34 & $<0.001^{*}$ \\
\cline { 1 - 5 } & 75 & 9 & 14 & 12.4 & \pm 1.22 & & \\
\hline
\end{tabular}

*Statistically significant

Table 2: Standard of Care items in OP case records and the results of audit process

\begin{tabular}{|l|c|c|c|}
\hline $\begin{array}{c}\text { Standard of Care items in OP case } \\
\text { records }\end{array}$ & $\begin{array}{c}\text { Baseline } \\
\text { audit (\%) } \\
\mathbf{N = 1 1 0}\end{array}$ & $\begin{array}{c}\text { Target } \\
\text { set } \\
(\mathbf{\%})\end{array}$ & $\begin{array}{c}\text { Compliance at } \\
\text { Post-audit (\%) } \\
\mathbf{N = 7 5}\end{array}$ \\
\hline $\begin{array}{l}\text { Patient details (name, age, sex and } \\
\text { address) }\end{array}$ & $110(100 \%)$ & $100 \%$ & $75(100 \%)$ \\
\hline Occupation of patient & $81(73.6 \%)$ & $90 \%$ & $69(92.0 \%)$ \\
\hline Drug allergies & $2(1.8 \%)$ & $50 \%$ & $19(25.3 \%)$ \\
\hline Past medical history & $78(70.9 \%)$ & $90 \%$ & $62(82.6 \%)$ \\
\hline Family \& social history & $61(55.4 \%)$ & $80 \%$ & $70(93.3 \%)$ \\
\hline Legibility"of writing & $108(98.1 \%)$ & $100 \%$ & $60(80.0 \%)$ \\
\hline Symptoms/complaints & $107(97.2 \%)$ & $100 \%$ & $75(100 \%)$ \\
\hline Physical examination finding & $105(95.4 \%)$ & $100 \%$ & $75(100 \%)$ \\
\hline Diagnosis & $69(62.7 \%)$ & $90 \%$ & $71(94.7 \%)$ \\
\hline Medication doses & $98(89.0 \%)$ & $100 \%$ & $74(98.6 \%)$ \\
\hline Medication duration & $7(6.4 \%)$ & $90 \%$ & $75(100 \%)$ \\
\hline Review date & $40(36.3 \%)$ & $80 \%$ & $71(94.6 \%)$ \\
\hline Name of examining Doctor/CRRI & $3(2.7 \%)$ & $50 \%$ & $71(94.6 \%)$ \\
\hline $\begin{array}{l}\text { Case sheet countersigned by the } \\
\text { medical officer? (if seen by CRRI) }\end{array}$ & $12(10.9 \%)$ & $60 \%$ & $58(77.3 \%)$ \\
\hline
\end{tabular}

*Cross verified by two members other than the auditor 


\section{Discussion}

Medical records are important documents that should be maintained at any institution providing medical care. It serves multiple purpose like recording the illness and treatment given, forms a medium of communication among the various doctors attending a patient, research of specific condition or treatment and for collection of health related statistics. ${ }^{5}$ Items that are documented on the patient case sheet varies depending on the patient's admission status and type of specialty care provided. Search of literature ${ }^{1,7-9}$ shows most of the patient case sheet audit have been done for hospital admitted patients in cancer, surgery, pediatrics, medicine etc. ward which focuses on obtaining informed consent form for various operative procedure and documentation of discharge summary. Even though pattern of case records differ between inpatient and outpatient and more emphasis is given to inpatient records, it is essential for all institutions providing health care to also maintain proper records of outpatients. The reason being that a severe presentation of a case will be mostly reflected in inpatient records whereas mildly ill cases are more likely to be inadequately documented in outpatient case-sheet, which is likely to affect continuity of care and opportunity can be missed in early detection of outbreak and for investigation purpose. ${ }^{10}$

In our study $100 \%$ of records had documented patients personal details (name, age, sex and address), similar results was obtained by Sinha et al. ${ }^{1}$ and Chamisa et al. ${ }^{8}$ in their study. Such information are not always written by the doctors but the nurses, admission staffs and record keeping staffs are also involved in the documentation process indicating a need to train all health care providers on the importance of maintaining accurate records, which has been suggested in a previous study ${ }^{11}$ also.

Our study shows poor reporting of drug allergy in pre $(1.5 \%)$ and post audit (25\%). Even Rohini et al. ${ }^{12}$ in their audit on documentation drug allergy in a tertiary care teaching hospital among inpatients and Farooq et al. ${ }^{13}$ among preoperative patients, identified majority of records being incomplete and inadequate. Even though in our setting most of the patients are unaware about their allergy status but asking and documenting such details by the treating physician creates awareness among patients and adds to quality of care.

Legibility of handwriting on medical records has been emphasized as a key to improve standards in medical records. ${ }^{14,15}$ This was the only criteria in the check list which declined in the post audit $(80.6 \%)$ compared to the baseline (98.6\%). Physician should understand the importance this criteria and make a conscious effort to improve it. Thompson et al. ${ }^{16}$ in their study on communication notes between the admitting team and the actually treating physician, identified $53 \%$ of communication failure mainly due to doctor's name not being legible or not documented. We identified that only $2.8 \%$ of records had the doctor's name written, but this improved drastically to $94.4 \%$ following the educational intervention. According to the Indian medical code of ethics ${ }^{17}$ it is essential for every treating physician to document their name on the patient file. Educating medical students and doctors on this aspects can improve quality of records and also creates a sense of responsibility among treating physician.

Medical profession has emphasized on the "five Rs" regarding medication- right drug, right time, right route, right patient and right patient. Two more Rs have been added by $\mathrm{WHO}^{18}$ to improve patient safety, these are right documentation and right of patient to question their prescription. Our study found recording of medication doses to be adequate (89\%) but duration of treatment was poor $(6.8 \%)$ but this improved after educational intervention to $100 \%$. Even Aronson et al. ${ }^{19}$ in their study suggested the need for giving continuous education to medical students and junior doctors on the necessity of correct drug prescriptions.

Our study found significant improvement in the documentation of OP case sheet between the pre and post audit following the educational intervention. Lack of awareness among the intern and medical officers could be the main reasons for poor documentation of certain items in the patient records. Similar findings have been reported in others studies ${ }^{20-24}$ also. The educational intervention used in the current study was found to be effective in improving the quality of casesheets.

Assessing legibility of hand writing can have subjective bias which we tried to eliminate by the process of cross verifying it with two other members apart from the principle auditor.

\section{Impact of the study}

The audit checklist has been included as part of the instructions given to interns by the medical officer at the beginning of their posting at the Urban Health Training Centre.

\section{Conclusion}

Auditing of case sheet at a Primary Health Training Centre is a very useful tool to monitor Interns and indirectly also sensitise the medical officers. The current audit that was done using standard guidelines, ensures uniformity across all outpatient case sheet and helps include essential details of occupation, social and personal history which is not only relevant for case management but also can be of use in future to conduct research related to common problems observed at the center and its catchment area. We also recommend that a structured educational training programme on proper OP documentation using WHO guidelines be conducted for interns at the beginning of their internship along with periodic review and regular auditing of sheets 
which will improve their documentation skills leading to better quality of patient care.

\section{Acknowledgment}

We thank Dr. Muhammad, Associate professor incharge of UHTC for his support to carry out the study, Dr. Sivamani, Professor of Community Medicine department, for guidance in statistical analysis; Dr. Subhashini and Dr. Lavanya, post graduates for their assistance in data collection; and the medical officers, interns and support staffs of UHTC, PSG-IMSR for their cooperation.

\section{Conflict of interest}

The authors declare that they have no conflict of interest.

\section{References}

1. Sinha, R. K., D. Saha, and N. R. Prathibha. "Assessment of Medical Documentation as Per joint Commission International." Journal of the Academy of Hospital Administration 21 (2009).

2. Rosenbloom, S. Trent, et al. "Data from clinical notes: a perspective on the tension between structure and flexible documentation." Journal of the American Medical Informatics Association 18.2 (2011):181-6.

3. Eight Steps to a Chart Audit for Quality. American Academy of Family Physicians. Available from : http://www.aafp.org/fpm/2008/0700/pa3.html

4. Thomas J. Medical records and issues in negligence. Indian journal of urology: IJU: journal of the Urological Society of India. 2009 Jul;25(3):384.

5. Medical Records Manual. A Guide for Developing Countries. Available from: http://www.wpro.who.int/publications/docs/MedicalReco rdsManual.pdf

6. Toolkits for Strengthening Primary Health Care. WHO. Jaanuary 2005. Available from: http://www.who.int/management/ToolkitsforStrengthenin gPHCAlbaniaPHC.pdf

7. Soto, Carlos M., Kenneth P. Kleinman, and Steven R. Simon. "Quality and correlates of medical record documentation in the ambulatory care setting."BMC health services research 2.1 (2002): 22 .

8. Chamisa I, Zulu BM. Setting the records straight $-\mathrm{a}$ prospective audit of the quality of case notes in a surgical department. S Afr J Surg 2007;45:92-5.

9. Somi MH. Are the medical records of high quality in teaching hospitals?. Journal of medical education. 2009 $\operatorname{Mar} 7 ; 5(2)$.

10. Training manual for medical officers for hospital based disease surveillance. Integrated Disease Surveillance Project. National Centre for Disease Control. Available from:

http://idsp.nic.in/WriteReadData/OldSite/usermanaul/man ual_for_MO.pdf

11. Saravi BM, Asgari Z, Siamian H, Farahabadi EB, Gorji AH, Motamed N, Fallahkharyeki M, Mohammadi R. Documentation of Medical Records in Hospitals of Mazandaran University of Medical Sciences in 2014: a Quantitative Study. Acta Informatica Medica. 2016 Jun;24(3):202.

12. Kalliat R, Smith N, Graham-Clarke E. An audit of the completeness and accuracy of allergy-status documentation. Management. 2017 Mar 8;12:17.
13. Farooq M, Kirke C, Foley K. Documentation of drug allergy on drug chart in patients presenting for surgery. Irish journal of medical science. 2008 Sep 1;177(3):2435.

14. Pullen I, Loudon J. Improving standards in clinical record-keeping. Advances in psychiatric treatment. 2006 Jul 1;12(4):280-6.

15. Health Informatics Unit. An Audit Tool for the RCP Generic Medical Record Keeping Standards. 2009 Apr:112.

16. Thompson A, Jacob K, Fulton J. Anonymized dysgraphia. J R Soc Med 2003;96:51

17. Code of Medical Ethics Regulations, 2002. Medical Council of India. Available from : https://mciindia.org/ActivitiWebClient/rulesnregulations/ codeofMedicalEthicsRegulations 2002

18. World Health Organization (WHO) patient safety curriculum guide for medicals schools. Topic 11 . Improving medication safety. Available from: http://www.who.int/patientsafety/education/curriculum/w ho_mc_topic-11.pdf

19. Aronson JK, Henderson G, Webb DJ, Rawlins MD. A prescription for better prescribing. BMJ. 2006;333:45960.

20. Siamian H, Ghafari AB, Aligolbandi K. Study on Rate of Knowledge, Attitude and Practice of Medical Students Towards Method of Medical Records Documentation. World Journal of Medical Sciences. 2008;3(1):24-7.

21. Ehrenberg A, Ehnfors M. Patient records in nursing homes. Scandinavian Journal of Caring Sciences. 1999 Jun 1;13(2):72-82.

22. Isoardi J, Spencer L, Sinnott M, Eley R. Impact of formal teaching on medical documentation by interns in an emergency department in a Queensland teaching hospital. Emergency Medicine Australasia. 2015 Feb 1;27(1):6-10.

23. McLean A, Lawlor J, Mitchell R, Kault D, O'kane C, Lees M. Impact of a structured intern education programme on clinical documentation in the emergency department. Emergency Medicine Australasia. 2015 Feb 1;27(1):29-34.

24. Asghari Z, Mardanshahi A, Farahabadi EB, Siamian H, Gorji AM, Saravi BM, Rezazadeh E, Paymard SP. The Quantitative Study of the Faculty Members Performance in Documentation of the Medical Records in Teaching Hospitals of Mazandaran University of Medical Sciences. Materia socio-medica. 2016 Jul 24;28(4):292. 